\title{
Review
}

Ophthalmologica

\section{Micronutrients in Age-Related Macular Degeneration}

\author{
Tariq Aslam $^{a}$ Cécile Delcourt ${ }^{b, c}$ Rufino Silva ${ }^{d}$ Frank G. Holz ${ }^{e}$ Anita Leys ${ }^{f}$ \\ Alfredo Garcià Layana ${ }^{g} \quad$ Eric Souied ${ }^{\text {h }}$ \\ ${ }^{a}$ Manchester Royal Eye Hospital, Central Manchester University Hospitals NHS Foundation Trust, Manchester \\ Academic Health Science Centre and Institute of Human Development, University of Manchester, Manchester,

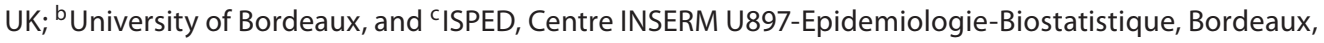 \\ France; ${ }^{d}$ University Hospital of Coimbra, University of Coimbra, and AIBILI, Coimbra, Portugal; ${ }^{\text {Department of }}$ \\ Ophthalmology, University of Bonn, Bonn, Germany; ${ }^{\mathrm{f} U n i v e r s i t y ~ H o s p i t a l s ~ L e u v e n, ~ L e u v e n, ~ B e l g i u m ; ~}{ }^{\mathrm{g}} \mathrm{Clinica}$ \\ Universidad de Navarra, Pamplona, Spain; ${ }^{\text {h}}$ Department of Ophthalmology, Hôpital Intercommunal de Créteil, \\ Créteil, France
}

\section{Key Words}

Macular degeneration - Nutrition - Micronutrients •

Vitamin $C \cdot \beta$-Carotene $\cdot$ Vitamin $\mathrm{E} \cdot$ Zinc $\cdot$ Lutein .

Zeaxanthin $\cdot$ Omega-3

\begin{abstract}
Several lines of evidence from in vitro and in vivo studies suggest that specific micronutrients may have beneficial effects in age-related macular degeneration (AMD). Such effects appear to be complex and may include filtering short wavelength light and attenuating oxidative and inflammatory damage as well as other structural and physiological factors. There is clinical evidence for potential benefits from vitamin $C, \beta$-carotene, vitamin $E$ and zinc, as well as emerging epidemiological and clinical data for the carotenoids lutein and zeaxanthin and for omega-3 fatty acids. A survey of the literature suggests that some specific micronutrients may be of value in treating or preventing AMD, but further prospective studies are needed to further identify and characterize their effects and place in therapy.
\end{abstract}

Copyright $\odot 2012$ S. Karger AG, Basel
(C) 2012 S. Karger AG, Basel

$0030-3755 / 13 / 2292-0075 \$ 38.00 / 0$

Accessible online at:

www.karger.com/oph

\section{Introduction}

Evidence for the benefit of micronutrients in age-related macular degeneration (AMD) comes from a variety of sources; biochemical, laboratory and animal studies indicate that specific micronutrients may have beneficial effects in filtering short wavelength light, decreasing oxidative and inflammatory damage and lowering apoptosis and angiogenesis, as well as other structural and physiological roles.

However, clinical and epidemiological studies are more direct indicators of potential benefit to patients, and human studies have involved both interventional and observational studies to provide evidence for dietary nutrients and supplements. Some support beneficial effects of good diet alone, whilst others show the effect of supplementary nutrients, at doses higher than can usually be obtained from diet alone. There is consensus about a potential beneficial effect of lutein/zeaxanthin and longchain omega-3. On the other hand, there are still some inconsistencies in reported benefits for different micronutrients and micronutrient combinations.

Such conflicting reports from clinical studies reflect the multifactorial nature of macular degeneration, wide variety of population nutrient intakes, different nutri- 
Table 1. AREDS categories 3 and 4 criteria

Category 3: one or two eyes with

- 20 intermediate size drusen (if soft drusen)

- or 65 intermediate size drusen (if no soft drusen)

- or one large druse $>125 \mu \mathrm{m}$

- or noncentral geographical atrophy

Category 4: one eye only with

- advanced AMD (central geographical atrophy/choroidal neovascularization)

Other information

- intermediate drusen $=63-125 \mu \mathrm{m}$

$-125 \mu \mathrm{m}=$ vein size at disc margin

- vision must be $6 / 9$ or better in best eye

There is a high level of evidence for reduced risk of development of advanced AMD using high-dose supplements in such patients.

ent doses and combinations in different trials, varying plasma levels and bioavailability depending on the individual and the variety of different genetic backgrounds.

The objective of the present review is to summarize the clinical and epidemiological evidence for the benefits of each of the major groups of micronutrients.

\section{Vitamin C, $\beta$-Carotene, Vitamin E and Zinc}

The strongest evidence for the benefit of these micronutrients comes from the extensive Age-Related Eye Disease Study (AREDS) [1], which was a large randomized controlled trial of ocular supplements in patients with a range of AMD. In patients classified with stage 3-4 AMD (table 1), it demonstrated a $25 \%$ reduction in the rate of deterioration to the late manifestations of the illness over a 5 -year period. The supplements (vitamin C, $\beta$-carotene, vitamin $\mathrm{E}$ and zinc) were given in doses greater than could be achieved through diet alone for a long period of time without significant side effects. Of note is that a significant proportion of the population was already on supplements and also that the complete combination of micronutrients was required; subgroups with only some of the nutrients failed to show significant benefit. It is also notable that the beneficial effect was proven only for conversion from early AMD to neovascular AMD, but not for that from early AMD to atrophic AMD. Furthermore, the genetic background seems to influence the impact of zinc supplementation.
Some results from epidemiological studies on these nutrients have been contradictory; for example, the $\mathrm{Pa}$ thologies Oculaires Liees a l'Age (POLA) Study (1999) [2] showed that the risk for late AMD is reduced by $82 \%$ in people with a high plasma level of vitamin E compared to people with a low level. The Rotterdam study (2005) also showed a decreased risk for AMD in subjects with high dietary intakes of $\beta$-carotene, vitamins $\mathrm{E}$ and $\mathrm{C}$ and zinc [3]. However, Taylor et al. [4] showed no association of vitamin E with AMD, and the Physicians' Health Study [5] failed to show any marked benefits for vitamins $\mathrm{C}$ or E. This perhaps reflects a greater dependence of this group of compounds on other confounding factors such as absorption rates, interaction with other micronutrients, exact doses of any oral supplements, bioavailability and baseline dietary intakes.

Overall, evidence for potential benefit of this group of micronutrients predominates. In addition to the largescale AREDS study of nutritional supplements, protective associations with high serum levels $[6,7]$ and higher dietary intakes have been described $[3,8,9]$.

It should be noted that high $\beta$-carotene intakes are contraindicated for smokers due to a potential increased risk for lung cancer. Continued need for $\beta$-carotene is being investigated in a follow-up of the AREDS study (AREDS II) along with the newer micronutrients discussed below. Pending the results of this study, many formulations have replaced $\beta$-carotene with other antioxidants.

Overall, for this group of micronutrients, there is the strongest level of evidence for benefit of oral supplements based on a large prospective multicenter randomized controlled trial. The benefits of these dietary and supplemental micronutrients have been robustly demonstrated to have a significant clinical effect. However, these benefits may be limited to precise populations and combinations of the nutrients.

\section{Lutein and Zeaxanthin (Carotenoids)}

This group of micronutrients has been investigated more recently. They are not usually associated with recommended daily amounts and have been available in the form of oral supplements more recently than vitamins A, $\mathrm{C}$ and $\mathrm{E}$ and zinc.

Most large-scale epidemiologic observational studies agree with the findings of beneficial effects of dietary intake of carotenoids, such as the Eye Disease Case-Control Study (USA) [10]. Studies based on plasma levels also found a correlation between high levels of lutein/zeaxan- 
thin in the plasma and low risk of AMD, e.g. the POLA Study [11] and Gale et al. [12].

Randomized controlled trials are scarce at present. A small randomized study using lutein supplementation in early AMD (Lutein Antioxidant Supplementation Trial) [13] showed a beneficial effect of lutein on the increase in macular pigment density. The evidence is not entirely in support of a protective role for these carotenoids; for example, the Carotenoids in Age-Related Eye Disease Study demonstrated a difference with higher levels of carotenoids only when analysis was limited to women under 75 years [14].

These nutrients are sequestered in the macula in a measurable form as macular pigment. Various studies have demonstrated an increase in macular pigment with carotenoid intake $[15,16]$.

Overall, various laboratory and clinical studies indicate that an increased intake of carotenoids may be associated with a reduced risk for AMD.

\section{Omega-3}

Omega-3 long-chain polyunsaturated fatty acids have been the most recent of those mentioned to have emerged as having potential benefit to those with AMD or those at risk of AMD. Although there have been no large-scale randomized trials published yet, observational data show a strong effect, perhaps greater than that of the other micronutrients discussed so far, comparing many thousands of patients overall. There is also a greater degree of consistency amongst different studies in showing significant benefits. For example, Seddon et al. [17] showed a relationship between omega-3 intake and reduced AMD. The AREDS report number 23 [18] and SanGiovanni et al. [19] showed that exudative AMD risk decreases with dietary omega-3 intake. Indeed, a meta-analysis of 9 studies and 88,974 participants demonstrated that high dietary intake of omega-3 fatty acids was associated with a $38 \%$ decreased risk for late AMD. Moreover, fish consumption at least twice a week was associated with a reduction in both early (24\% reduction) and late (33\% reduction) AMD [20].

Other population studies confirm this link between dietary intake of omega-3 and lower levels of AMD [2123]. The US Twin Study of Age-Related Macular Degeneration [17], the Nurses' Health Study and the Health Professionals Follow-Up Study [24] concur, as do studies by Christen et al. [25], Seddon et al. [17], Swenor et al. [26] and Merle et al. [27], as well as the POLA and Nutrition
Table 2. An overview of micronutrient dosages

\begin{tabular}{llllc}
\hline & $\begin{array}{l}\text { Dosages in prospective } \\
\text { studies, mg/day }\end{array}$ & $\begin{array}{l}\text { European limits } \\
\text { mg/day }\end{array}$ & $\begin{array}{l}\text { Dosage } \\
\text { variations } \\
\text { mg/day }\end{array}$ \\
\hline Vitamin C & 500 & AREDS 1 & 180 & $300-500$ \\
Vitamin E & 266 & AREDS 1 & 30 & $100-266$ \\
Zinc & $80 / 25$ & AREDS 1/2 & 15 & $25-80$ \\
Copper & 2 & AREDS 1 & & $6-20$ \\
Lutein & 10 & AREDS 2 & & $0-2$ \\
Zeaxanthin & 2 & AREDS 2 & & $600-4,000$ \\
Omega-3 & 1,000 & AREDS 2 & & \\
\hline
\end{tabular}

(POLANUT) study [28]. There is thus a broad consensus on the association between high omega- 3 intake and low levels of AMD of all stages.

Sufficient omega-3 long-chain polyunsaturated fatty acids are mainly derived from fish and seafood and are difficult to obtain from purely vegetarian sources.

Studies in the field of omega- 3 have been ongoing for the last decade. Although there have not yet been any large randomized controlled trials published, there is strong consistency of results from the studies on omega-3, and the level of benefits that are theoretically gained appear to be the highest from amongst all micronutrient groups.

\section{Conclusions}

Various findings are in favor of a role of several specific micronutrients in the treatment or prevention of AMD. Patients with AREDS level 3-4 AMD (table 1) should be prescribed supplements as per AREDS, which appears to have an effect beyond that which could be obtained through diet alone. For patients with earlier forms of AMD, clear evidence is still lacking.

Dietary intakes of vitamin E, zinc and carotenoids are low in Europe, and some vulnerable groups lack sufficient vitamin C intake. Omega-3 intake is also poor in the aged population in Europe [29,30], but an increase in the omega-3/omega- 6 ratio can be obtained by regular oily fish consumption. Thus, it is important to encourage a healthy balance of all micronutrient subgroups as part of a balanced healthy diet, along with good fluid intake. Recommended dosages for these micronutrients, according to present evidence, are summarized in table 2.

Vitamin A, lutein and zeaxanthin are obtained from peas, spinach, kale, watercress, turnip, sprouts, lettuce, broccoli and yellow foods (corn, orange, eggs). Vitamin C 
is sourced from citrus fruits and juices, kiwi, cabbage and cauliflower. Vitamin E can be provided by wholegrain cereals, vegetable oils, nuts, turnips, beetroot, tomatoes, pumpkins, asparagus and broccoli.

Zinc is present in beef, pork, chicken, oysters, fortified cereals, baked beans, yoghurt and chickpeas, whilst omega-3 fatty acids are principally obtained from oily fish and seafood and specific vegetable oils (rapeseed, soybean, walnut).
Many patients may find it difficult to maintain adequately high intake of key micronutrients, due, for example, to disliking or being prohibited from eating key foods, difficulty eating in general, difficulty accessing key foods or general difficulties in maintaining a diet rich in all the above micronutrients at all times.

For these patients, supplements may be preferred, and those containing all three groups of micronutrients described may be prudent.

\section{References}

1 Age-Related Eye Disease Study Research Group: A randomized, placebo-controlled, clinical trial of high-dose supplementation with vitamins $\mathrm{C}$ and $\mathrm{E}$, beta carotene, and zinc for age-related macular degeneration and vision loss: AREDS report no. 8. Arch Ophthalmol 2001;119:1417-1436.

-2 Delcourt C, Cristol JP, Tessier F, Leger CL, Descomps B, Papoz L: Age-related macular degeneration and antioxidant status in the POLA study. POLA Study Group. Pathologies Oculaires Liees a l'Age. Arch Ophthalmol 1999;117:1384-1390.

> van Leeuwen R, Boekhoorn S, Vingerling JR, Witteman JC, Klaver CC, Hofman A, de Jong PT: Dietary intake of antioxidants and risk of age-related macular degeneration. JAMA 2005;294:3101-3107.

-4 Taylor HR, Tikellis G, Robman LD, McCarty CA, McNeil JJ: Vitamin E supplementation and macular degeneration: randomised controlled trial. BMJ 2002;325:11.

5 Christen WG, Ajani UA, Glynn RJ, Manson JE, Schaumberg DA, Chew EC, Buring JE, Hennekens CH: Prospective cohort study of antioxidant vitamin supplement use and the risk of age-related maculopathy. Am J Epidemiol 1999; 149:476-484.

-6 Antioxidant status and neovascular age-related macular degeneration. Eye Disease Case-Control Study Group. Arch Ophthalmol 1993;111:104-109.

7 West S, Vitale S, Hallfrisch J, Muñoz B, Muller D, Bressler S, Bressler NM: Are antioxidants or supplements protective for age-related macular degeneration? Arch Ophthalmol 1994;112:222-227.

-8 VandenLangenberg GM, Mares-Perlman JA, Klein R, Klein BE, Brady WE, Palta M: Associations between antioxidant and zinc intake and the 5-year incidence of early agerelated maculopathy in the Beaver Dam Eye Study. Am J Epidemiol 1998;148:204-214.

-9 Tan JS, Wang JJ, Flood V, Rochtchina E, Smith W, Mitchell P: Dietary antioxidants and the long-term incidence of age-related macular degeneration: the Blue Mountains Eye Study. Ophthalmology 2008; 115 :334341.
10 Seddon JM, Ajani UA, Sperduto RD, Hiller R, Blair N, Burton TC, Farber MD, Gragoudas ES, Haller J, Miller DT, Lawrence A. Yannuzzi LA, Willett W: Dietary carotenoids, vitamins $A, C$, and $E$, and advanced age-related macular degeneration. Eye Disease Case-Control Study Group. JAMA 1994;272: 1413-1420.

11 Delcourt C, Carriere I, Delage M, BarbergerGateau P, Schalch W: Plasma lutein and zeaxanthin and other carotenoids as modifiable risk factors for age-related maculopathy and cataract: the POLA Study. Invest Ophthalmol Vis Sci 2006;47:2329-2335.

12 Gale CR, Hall NF, Phillips DI, Martyn CN: Lutein and zeaxanthin status and risk of agerelated macular degeneration. Invest Ophthalmol Vis Sci 2003;44:2461-2465.

13 Richer S, Stiles W, Statkute L, Pulido J, Frankowski J, Rudy D, Pei K, Tsipursky M, Nyland J: Double-masked, placebo-controlled, randomized trial of lutein and antioxidant supplementation in the intervention of atrophic age-related macular degeneration: the Veterans LAST study (Lutein Antioxidant Supplementation Trial). Optometry 2004;75:216-230.

14 Moeller SM, Parekh N, Tinker L, Ritenbaugh C, Blodi B, Wallace RB, Mares JA; CAREDS Research Study Group: Associations between intermediate age-related macular degeneration and lutein and zeaxanthin in the Carotenoids in Age-related Eye Disease Study (CAREDS): ancillary study of the Women's Health Initiative. Arch Ophthalmol 2006;124:1151-1162.

15 Weigert G, Kaya S, Pemp B, Sacu S, Lasta M, Werkmeister RM, Dragostinoff N, Simader C, Garhöfer G, Schmidt-Erfurth U, Schmetterer L: Effects of lutein supplementation on macular pigment optical density and visual acuity in patients with age-related macular degeneration. Invest Ophthalmol Vis Sci 2011;52:8174- 8178.

16 Koh HH, Murray IJ, Nolan D, Carden D, Feather J, Beatty S: Plasma and macular responses to lutein supplement in subjects with and without age-related maculopathy: a pilot study. Exp Eye Res 2004;79:21-27.
17 Seddon JM, George S, Rosner B: Cigarette smoking, fish consumption, omega- 3 fatty acid intake, and associations with age-related macular degeneration: the US Twin Study of Age-Related Macular Degeneration. Arch Ophthalmol 2006;124:995-1001.

18 SanGiovanni JP, Chew EY, Agrón E, Clemons TE, Ferris FL 3rd, Gensler G, Lindblad AS, Milton RC, Seddon JM, Klein R, Sperduto RD; Age-Related Eye Disease Study Research Group: The relationship of dietary omega-3 long-chain polyunsaturated fatty acid intake with incident age-related macular degeneration: AREDS report no. 23. Arch Ophthalmol 2008;126:1274-1279.

19 SanGiovanni JP, Agron E, Clemons TE, Chew EY: Omega-3 long-chain polyunsaturated fatty acid intake inversely associated with 12-year progression to advanced agerelated macular degeneration. Arch Ophthalmol 2009;127:110-112.

20 Chong EW-T, Kreis AJ, Wong TY, Simpson JA, Guymer RH: Dietary omega-3 fatty acid and fish intake in the primary prevention of age-related macular degeneration. A systematic review and meta-analysis. Arch Ophthalmol 2008; 126:826-833.

21 Chong EW-T, Robman LD, Simpson JA, Hodge AM, Aung KZ, Dolphin TK, English DR, Giles GG, Guymer RH: Fat consumption and its association with age-related macular degeneration. Arch Ophthalmol 2009; 127:674-680

22 Chua B, Flood V, Rochtchina E, Wang JJ, Smith W, Mitchell P: Dietary fatty acids and the 5-year incidence of age-related maculopathy. Arch Ophthalmol 2006;124:981-986.

23 Augood C, Chakravarthy U, Young I, Vioque J, de Jong PT, Bentham G, Rahu M, Seland J, Soubrane G, Tomazzoli L, Topouzis F, Vingerling JR, Fletcher AE: Oily fish consumption, dietary docosahexaenoic acid and eicosapentaenoic acid intakes, and associations with neovascular age-related macular degeneration. Am J Clin Nutr 2008;88:398406. 
24 Cho E, Hung S, Willett WC, Spiegelman D, Rimm EB, Seddon JM, Colditz GA, Hankinson SE: Prospective study of dietary fat and the risk of age-related macular degeneration. Am J Clin Nutr 2001;73:209-218.

25 Christen WG, Schaumberg DA, Glynn RJ, Buring JE: Dietary omega-3 fatty acid and fish intake and incident age-related macular degeneration in women. Arch Ophthalmol 2011;129:921-929.

-26 Swenor BK, Bressler S, Caulfield L, West SK: The impact of fish and shellfish consumption on age-related macular degeneration. Ophthalmology 2010;117:2395-2401.
27 Merle B, Delyfer MN, Korobelnik JF, Rougier MB, Colin J, Malet F, Féart C, Le Goff M, Dartigues JF, Barberger-Gateau P, Delcourt C: Dietary omega-3 fatty acids and the risk for age-related maculopathy: the Alienor Study. Invest Ophthalmol Vis Sci 2011;52: 6004-6011.

28 Delcourt C, Carriere I, Cristol JP, Lacroux A, Gerber M: Dietary fat and the risk of age-related maculopathy: the POLANUT study. Eur J Clin Nutr 2007;61:1341-1344.
Carriere I, Delcourt C, Lacroux A Gerber M Nutrient intake in an elderly population in southern France (POLANUT): deficiency in some vitamins, minerals and omega-3 PUFA. Int J Vitam Nutr Res 2007;77:57-65.

30 Feart C, Jutand MA, Larrieu S, Letenneur L, Delcourt C, Combe N, Barberger-Gateau P: Energy, macronutrient and fatty acid intake of French elderly community dwellers and association with socio-demographic characteristics: data from the Bordeaux sample of the Three-City Study. Br J Nutr 2007;98: 1046-1057. 